\title{
Video games bring new aspects to medical education and training
}

\author{
- Cite as: CMAJ 2019 September 16;191:E1034-5. doi: 10.1503/cmaj.1095784
}

Posted on cmajnews.com on August 27, 2019.

\begin{abstract}
A teenager sitting on a couch with a video game controller, trying for the umpteenth time to defeat an ogre guarding a cave, could have more in common with a doctor than you might think. The use of video games to teach clinical knowledge and skills is growing in popularity, and advocates for gaming in medical training say it integrates solid principles of learning and skills-acquisition.

"Games follow a good instructional framework," said Andrea Gauthier, who is pursuing postdoctoral work at Univer-
\end{abstract}

sity College London on how gaming can help students avoid misconceptions in science and mathematics.

Her perspective has been shaped not only by her personal experience with commercial role-playing games, but also from her doctoral work at the University of Toronto's Institute of Medical Science. That's where she examined how a welldesigned game can abide by established principles of learning, such as setting objectives and encouraging recall, as well as providing guidance, feedback and a measure of performance.
Some may be skeptical of the value of an activity typically associated with sword fights or space battles, but Gauthier insists gaming can produce positive educational outcomes. She coauthored a paper in the Journal of Medical Internet Research that reviewed several dozen studies comparing learning outcomes of traditional educational formats, such as textbooks or workshops, to those of electronic approaches that offer some aspect of gamification to health training. The findings indicated that learning through games was at least as successful as other

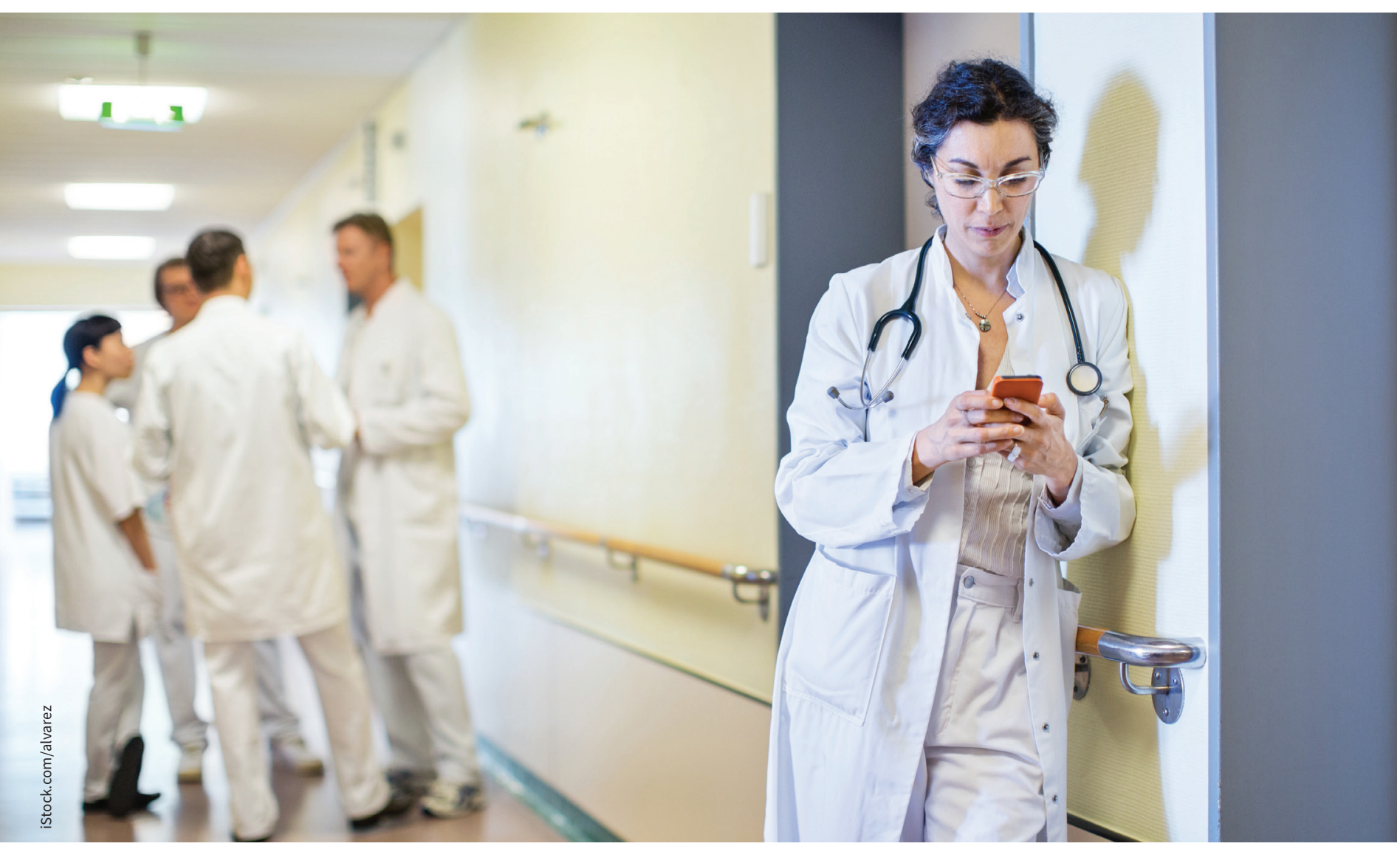

In the United States, doctors can earn continuing medical education credits by playing educational video games on their smartphones. 
formats and, in some cases, "more effective for improving knowledge, skills, and satisfaction." The authors acknowledged, however, that "available evidence is mostly of low quality" and said further research is needed.

"You're seeing an integration of concepts into gaming mechanics," explained Gauthier, adding that early versions of many educational games consisted of trivia challenges that offered little more than a textbook quiz on a computer monitor. Her own academic work has considered the more ambitious design of a game to help science students grasp subtle scientific ideas, such as the randomness of molecular and cellular interactions.

"This is where games really shine, when it comes to these complex concepts," she said. A person can simply memorize information to pass a quiz, but a broader appreciation of a complicated concept emerges through gameplay, during which a user either succeeds or fails based on how they use information in specific scenarios.

At St. Michael's Hospital in Toronto, staff can play a game that allows them to practise the critical steps necessary to treat diabetic ketoacidosis (DKA). Dr. Catherine $\mathrm{Yu}$, an associate scientist with St. Michael's Li Ka Shing Knowledge Institute, oversaw the DKA project and coauthored a description of its impact for the Journal of General Internal Medicine.

"DKA is a rare entity and you might not have a chance to manage it, but it's a lifethreatening emergency that you need to practise a few times to get it right," she said. "If you're able to simulate a clinical situation like that without the risk of harming a patient, then that would be a good learning tool." She plans to publish a more detailed study soon comparing the effectiveness of self-directed, game-based learning to that of standard, hands-on training sessions.

If nothing else, one clear advantage associated with games is an enhanced ability to learn from failure. Just as being killed by the ogre repeatedly eventually allows a gamer to figure out how to solve that problem, losing a virtual patient to DKA can be an effective way of learning how not to lose a real patient.

According to Gauthier, the best educational games make the most of this advantage, so users actually learn rather than just rack up points. "Doctors should be looking for targeted concepts to be integrated within the gameplay itself," she said. "It's not as though game elements are just tacked on in a superfluous way; the actual concepts are deeply embedded into the gameplay, so you can't succeed in the game if you're not learning the concepts."

In the United States, physicians can earn continuing medical education credits for playing smartphone games created by a company called Level Ex, which has more than 400,000 medical professionals among its users. The company has games targeted to anesthesiologists, gastroenterologists, pulmonologists and cardiologists. The games are designed to test knowledge, spatial reasoning and fast-paced decision making, and their popularity among doctors "is ridiculous," Level Ex's CEO Sam Glassenberg told MobiHealthNews, adding that the company can't make games "fast enough to meet the demand."

Tim Lougheed, Bath, Ont. 